\title{
Influence of Dew Period and Temperature on Foliar Infection of Greenhouse-Grown Tomato by Colletotrichum coccodes
}

J. M. Byrne, Graduate Assistant, M. K. Hausbeck, Assistant Professor, C. Meloche, Former Undergraduate Research Assistant, and A. M. Jarosz, Associate Professor, Department of Botany and Plant Pathology, Michigan State University, East Lansing 48824

\begin{abstract}
Byrne, J. M., Hausbeck, M. K., Meloche, C., and Jarosz, A. M. 1998. Influence of dew period and temperature on foliar infection of greenhouse-grown tomato by Colletotrichum coccodes. Plant Dis. 82:639-641.

Effects of temperature, duration of leaf wetness, and leaf position on foliar infection of greenhouse-grown tomato (cv. Bonnie Best) by Colletotrichum coccodes were determined by inoculating plants with $C$. coccodes $\left(5.0 \times 10^{5}\right.$ conidia per $\left.\mathrm{ml}\right)$ and keeping them in a dew chamber for $0,4,8,12,16,20$, or $24 \mathrm{~h}$ of wetting at 15,20 , or $25^{\circ} \mathrm{C}$. One week after inoculation, leaf disks were placed on the surface of an amended medium on which colonies of $C$. coccodes were compact and easily identified, and severity of infection was quantified after 4, 6, and 8 days. There was no infection of plants incubated at $15^{\circ} \mathrm{C}$, while plants kept at 20 or $25^{\circ} \mathrm{C}$ had increasing numbers of colonies when leaf wetness duration was extended beyond 12 and $8 \mathrm{~h}$, respectively. Leaf position had a significant effect, with leaves tending to increase in susceptibility as they age. After $24 \mathrm{~h}$ of leaf wetness at $25^{\circ} \mathrm{C}$, the mean number of colonies per leaf disk from top, middle, and bottom leaves was $23.8,29.0$, and 34.0, respectively.
\end{abstract}

Additional keywords: anthracnose, fungal disease, semi-selective media, senescence

In Michigan, commercial production of tomatoes grown for fresh market and processing was valued at \$20.1 million in 1995 (18). Anthracnose (Colletotrichum coccodes (Wallr.) S.J. Hughes) is a devastating fungal disease of processing tomatoes grown in the eastern and midwestern United States. Fruit grown for processing is harvested when fully ripe and is especially vulnerable to infection by $C$. coccodes $(10,12)$. Anthracnose fruit rot is a less significant problem in fresh market tomatoes, because fruit is harvested at the mature green stage. Although $C$. coccodes may infect green fruit, symptoms do not develop until fruit ripening occurs. Latency of green fruit infections can, however, be overcome by exposure to low temperatures in the field or in storage $(5,14)$.

Anthracnose fruit rot symptoms begin as small, dark, sunken lesions that have a water-soaked appearance. Lesions increase in diameter and coalesce, leaving a large, sunken, soft area (25). Under favorable temperatures, lesions on ripe fruit become visible within 5 to 6 days after infection (5). As lesions mature, setose sclerotia develop from the stromata of acervuli pro-

Corresponding author: J. M. Byrne

E-mail: byrnejm@pilot.msu.edu

Accepted for publication 14 March 1998.

Publication no. D-1998-0420-02R

(C) 1998 The American Phytopathological Society duced beneath the infected fruit tissue (25). In subsequent years, infections of tomato fruit can be initiated from conidia produced in acervuli $(10,25)$ arising from sclerotium-infested tomato debris overwintering in soil $(8,15)$.

Fungicides are essential for processing tomato production in the Midwest due to significant disease pressure and stringent thresholds for allowable anthracnose fruit rot (20). When unmanaged, fruit rot incidence can be as high as $90 \%$ (3). Under severe disease pressure, reduced protection resulting from a reduced number of sprays may result in a high incidence of anthracnose fruit rot causing rejection of the crop at the processing site and financial loss despite expenditures on fungicides (3).

C. coccodes is not reported to cause foliar blight on tomato, although it can infect foliage, producing small necrotic spots with chlorotic haloes, which may sporulate under favorable environmental conditions $(15,26)$. Researchers have made conflicting conclusions regarding the significance of foliar inoculum on fruit infections. Kendrick and Walker (15) inoculated plants with an albino, morphologically recognizable strain of $C$. coccodes. After failing to recover the albino strain from infected fruit, the researchers concluded that sporulation of $C$. coccodes in foliar lesions was not a significant source of secondary inoculum for fruit infection (15). However, these results may have been influenced by the reduced ability of albino isolates to penetrate tissue (17). In contrast, Pantidou and Schroeder (19) concluded from studies using morphologically recognizable strains that $C$. coccodes can infect foliage and subsequently sporulate, providing significant inoculum for fruit infection. Current management strategies do not recognize foliar sporulation as a significant source of inoculum for fruit infection.

Illman (13) conducted histological studies of foliar infection by $C$. coccodes and determined that appressoria formed by $19 \mathrm{~h}$ after inoculation and that a germ tube was present and infected a neighboring epidermal cell by $42 \mathrm{~h}$ after inoculation. Byrne et al. (2) further researched the infection process of $C$. coccodes on tomato foliage incubated at $25^{\circ} \mathrm{C}$ under continuous leaf wetness. Two hours after inoculation, $17.9 \%$ of conidia had germinated, with maximum germination $(68.3 \%) 24 \mathrm{~h}$ after inoculation. Appressoria melanization began $4 \mathrm{~h}$ after inoculation $(0.7 \%)$ and increased linearly with time. Infection vesicles were present $22 \mathrm{~h}$ after inoculation, indicating successful infection.

The objective of this study was to determine the temperature and duration of leaf wetness necessary for $C$. coccodes to infect tomato foliage. A preliminary report has been published (11).

\section{MATERIALS AND METHODS}

Tomato seedlings (cv. Bonnie Best) were grown in a $20^{\circ} \mathrm{C}$ research greenhouse in 1.5-liter clay pots containing Baccto soilless medium (Michigan Peat Company, Houston, TX). Plants were watered daily or as needed and fertilized (20-20-20, $\mathrm{N} / \mathrm{P}\left[\mathrm{P}_{2} \mathrm{O}_{5}\right] / \mathrm{K}\left[\mathrm{K}_{2} \mathrm{O}\right]$ ) twice weekly.

An isolate of $C$. coccodes obtained from a naturally infected ripe tomato fruit was grown on medium containing V8 juice (30\%) and agar (2\%) (Difco Laboratories, Detroit, MI) (4) in $100 \times 15 \mathrm{~mm}$ petri dishes at $20^{\circ} \mathrm{C}$ under continuous coolwhite fluorescent light (1). Before inoculation, 7- to 14-day-old cultures were flooded with $10 \mathrm{ml}$ of sterile distilled water and gently scraped with a glass rod. A conidial suspension was adjusted to $1 \times 10^{5}$ conidia per $\mathrm{ml}$ using a hemacytometer. Plants with seven to eight nodes were spray-inoculated to runoff with the suspension. A top, middle, and bottom leaf was tagged on each plant. Immediately after inoculation, plants were placed in a dew chamber (Model I-35DL, Percival Mfg. Co., Boone, IA) in continuous darkness at 
15,20 , or $25^{\circ} \mathrm{C}$ with continuous dew. Dew formed on the plants within $1 \mathrm{~h}$ of their placement into the chamber. Plants remained in the dew chamber for $0,4,8,12$, 16,20 , or $24 \mathrm{~h}$. Upon removal from the dew chamber, plants were maintained in a laboratory at $21^{\circ} \mathrm{C}$ and a $16-\mathrm{h}$ photoperiod for 7 days before explants were removed. Three plants were used for each treatment, and the experiment was replicated three times.
With a 1.3-cm-diameter cork borer, six healthy-appearing leaf disks were excised from a fully expanded, previously marked, top, middle, and bottom leaf from each plant. Leaf disks were surface-disinfested in $0.525 \%$ sodium hypochlorite and 6 drops of Tween 20 per liter for approximately $60 \mathrm{~s}$, triple rinsed in sterile distilled water, and blotted dry. Leaf disks were plated onto semi-selective V8 media (300 $\mathrm{ml}$ of double filtered $\mathrm{V} 8$ juice, $700 \mathrm{ml}$ of
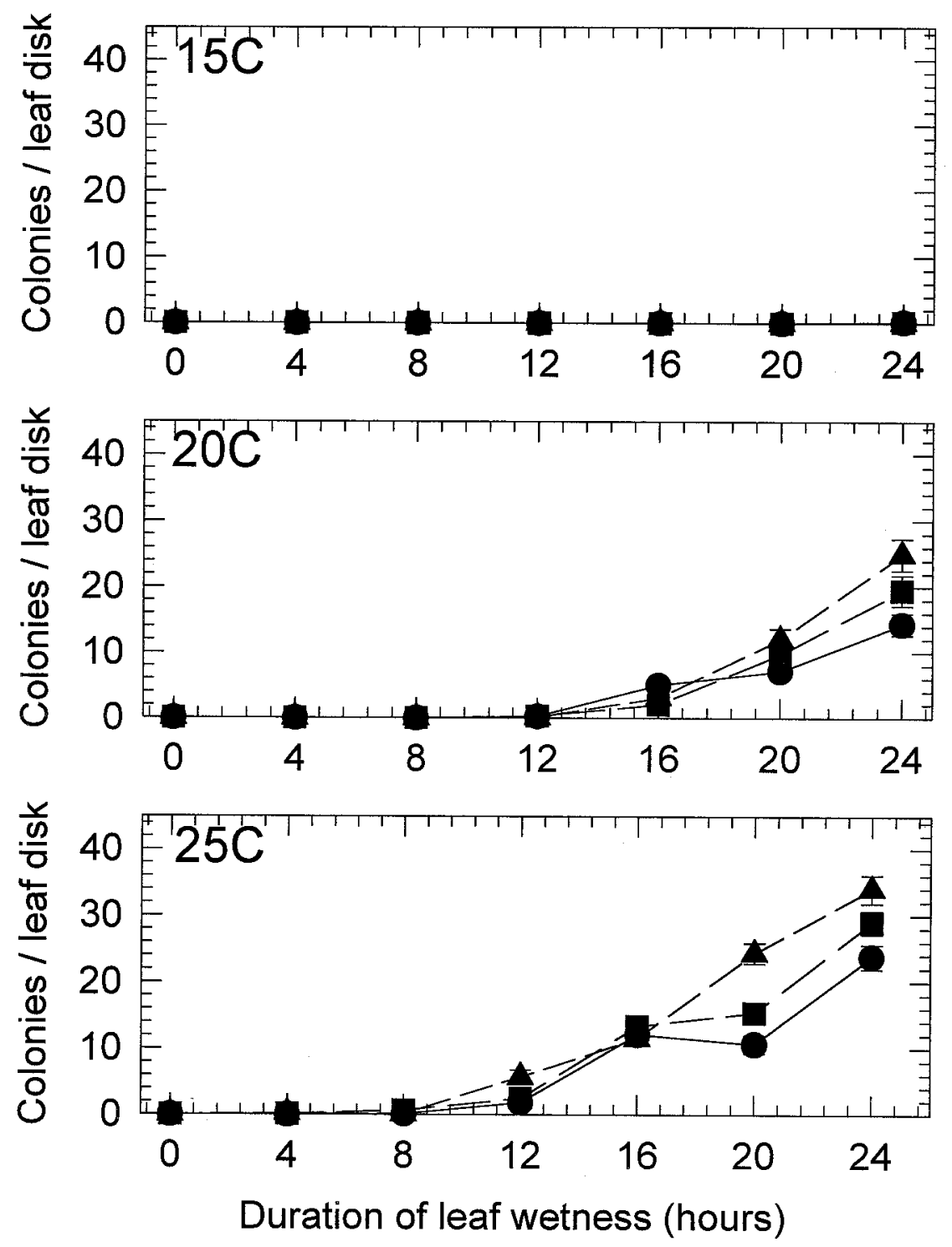

Fig. 1. Mean number of colonies of Colletotrichum coccodes on leaf disks removed from top (๑), middle ( $\mathbf{\square})$, and bottom $(\boldsymbol{\Delta})$ leaves of greenhouse-grown tomato plants incubated at 15,20 , and $25^{\circ} \mathrm{C}$ in a dew chamber for $0,4,8,12,16,20$, and $24 \mathrm{~h}$. Error bars represent standard errors of the mean.

Table 1. Analysis of variance testing for the effect of temperature, hours of leaf wetness, plant, and leaf position on the number of Colletotrichum coccodes colonies per leaf disk

\begin{tabular}{lrccc}
\hline Source & df & Mean square & $\boldsymbol{F}$ value & Prob > $\boldsymbol{F}$ \\
\hline Temperature (T) & 2 & $21,907.61$ & 4.16 & 0.0423 \\
Hours of leaf wetness (W) & 6 & $18,457.97$ & 3.51 & 0.0306 \\
$\mathrm{~T}^{*} \mathrm{~W}$ & 12 & $5,261.44$ & 36.99 & 0.0001 \\
Plant $\left(\mathrm{T}^{*} \mathrm{~W}\right)(\mathrm{P})$ & 42 & 142.26 & 0.13 & 0.9984 \\
Leaf position (LP) & 2 & $1,067.08$ & 28.91 & 0.0001 \\
Error & 3,337 & 36.91 & & \\
\hline
\end{tabular}

640 Plant Disease / Vol. 82 No. 6

double distilled water, and $20 \mathrm{~g}$ of Difco Bacto agar) amended after autoclaving with $0.14 \mathrm{~g}$ of $50 \%$ WP benomyl (DuPont, Wilmington, DE), $0.13 \mathrm{~g}$ of $75 \% \mathrm{WP}$ pentachloronitrobenzene (Uniroyal, Middlebury, CT), $0.1 \mathrm{~g}$ of streptomycin sulfate (Sigma Chemical Company, St. Louis, MO), $0.1 \mathrm{~g}$ of tetracycline $\mathrm{HCl}$ (Sigma), and $0.1 \mathrm{~g}$ of chloramphenicol (Sigma) to support discreet $C$. coccodes colonies that could be quantified $(7,11)$. Three leaf disks were placed in a $100 \times 15 \mathrm{~mm}$ petri dish and incubated at $22^{\circ} \mathrm{C}$ under $12 \mathrm{~h}$ of continuous cool-white fluorescent light. $C$. coccodes colonies growing on each leaf disk were counted with the aid of a dissecting scope $(\times 6.5) 4,6$, and 8 days after plating. Colonies that could not initially be identified on sight were cultured on a nonamended V8 juice medium (2) and identified. Data presented were taken 8 days after plating, when the maximum number of colonies was present.

Analysis of variance was done using the ANOVA procedure of the Statistical Analysis System (SAS Institute, Cary, NC). The experiment was analyzed as a mixed design, with plant being nested within each temperature by leaf wetness combination. An initial analysis found no significant effect due to replicate, although the interaction between replicate and hours of leaf wetness was significant. However, since there were no consistent trends across observation days (i.e., the 4-, 6-, and 8 -day counts for a given petri dish), replicate was not included as a variable in the final analysis. The petri dish in which a leaf disk was incubated had no effect on the final number of colonies formed. Therefore, the degrees of freedom associated with petri dish were incorporated into the error term for the final analysis.

\section{RESULTS}

Following inoculation and incubation, tomato foliage appeared healthy, with no symptoms of disease. However, when leaf disks were plated onto semi-selective agar, discrete $C$. coccodes colonies developed which were easily quantified (Fig. 1).

Analysis of variance indicated a highly significant interaction between temperature and the duration of leaf wetness (Table 1). The interaction was due largely to a lack of infection at all wetness durations for plants incubated at $15^{\circ} \mathrm{C}$, whereas plants kept at 20 or $25^{\circ} \mathrm{C}$ displayed similar patterns of increasing numbers of colonies when leaf wetness duration was extended beyond 12 h (Fig. 1). However, the numbers of colonies were higher for plants incubated at $25^{\circ} \mathrm{C}$ than for plants incubated at $20^{\circ} \mathrm{C}$ for a similar length of leaf wetness.

Leaves within a plant became progressively more susceptible as they aged. This resulted in a significant leaf position effect (Table 1). At an incubation temperature of $25^{\circ} \mathrm{C}$ and $24 \mathrm{~h}$ of leaf wetness, the mean numbers of colonies per leaf disk for the 
top (youngest), middle, and bottom (oldest) leaves were $23.8,29.0$, and 34.0, respectively. Leaf position did not affect the mean number of colonies per leaf disk on plants incubated at $15^{\circ} \mathrm{C}$. There was no plant effect in Table 1.

\section{DISCUSSION}

The interaction of temperature and hours of leaf wetness significantly influenced foliar infection of $C$. coccodes on greenhouse-grown tomatoes. In our study, temperatures of 20 and $25^{\circ} \mathrm{C}$ favored foliar infection when accompanied by a minimum of 16 and $12 \mathrm{~h}$ of leaf wetness, respectively. Foliar infection did not occur on disks incubated at $15^{\circ} \mathrm{C}$ when leaf wetness ranged from 0 to $24 \mathrm{~h}$. Leaf wetness periods of $12 \mathrm{~h}$ or greater during warm periods $\left(\geq 20^{\circ} \mathrm{C}\right)$ occur frequently in Michigan and other midwestern states, creating favorable conditions for $C$. coccodes infection. Earlier studies examining the infection of tomato foliage did not investigate the effects of environmental parameters on infection $(2,13,15,19)$. Dillard $(4,5)$ determined the optimal temperatures for fruit infection $\left(25^{\circ} \mathrm{C}\right)$, mycelial growth of $C$. coccodes on $\mathrm{V} 8$ juice agar $\left(28^{\circ} \mathrm{C}\right)$, and germination on water agar $\left(22^{\circ} \mathrm{C}\right)$.

The methodology used in this study allowed the quantification of presumably latent $C$. coccodes infections from healthyappearing foliage. Colonies observed on leaf disks were not likely the result of conidia remaining on the leaf surface following inoculation, which had not completed the infection process because the surface was disinfested with sodium hypochlorite prior to plating. The environmental parameters (16 or $12 \mathrm{~h}$ of leaf wetness at 20 or $25^{\circ} \mathrm{C}$, respectively) established in our study as requirements for successful $C$. coccodes colonization of leaf tissue coincide with earlier observations where it was shown that $56 \%$ of germinated conidia produced melanized appressoria $12 \mathrm{~h}$ after inoculation at $25^{\circ} \mathrm{C}(2)$.

Leaf disks removed from bottom leaves contained higher numbers of colonies than leaf disks removed from top and middle leaves. Zulfiqar et al. (27) observed that senescent or wounded tissue can be colonized by $C$. gloeosporioides, and abundant acervuli are produced under moist conditions. Mechanical force is a major component of tissue penetration and subsequent infection by Colletotrichum spp. (16). Membrane deterioration is often associated with senescence (6). The senescing bottom leaves may have been more easily penetrated by $C$. coccodes than the younger tissue of middle and top leaves, thus allowing the higher number of colonies observed on the bottom leaf disks.

In commercial processing tomato production, ethylene is applied before harvest to induce foliar senescence and uniform ripening of the fruit for improved efficiency of mechanical harvesting. Ethylene induces germination and appressorium formation on glass microscope slides in some Colletotrichum spp. (9). The increased susceptibility of senescing leaves to $C$. coccodes may have epidemiological consequences that impact fruit disease incidence, depending on the significance of foliar inoculum in fruit infection.

The factor that triggered the release of latency in this system is not known. Senescence resulting from excision of the leaf disks or placement of the disks onto a nutrient rich medium may have induced the latent foliar infections to produce colonies. However, the latent stage of C. gloeosporioides, which commonly occurs in avocado, is not a result of a lack of nutrients in the host $(21,22,24)$. Rather, the metabolism during ripening of an antifungal compound which inhibits germ tube elongation and appressorium development is suspected to be the basis of breaking latency of $C$. gloeosporioides infections in avocado (23). Determination of the environmental conditions necessary for infection of tomato foliage by $C$. coccodes may be helpful to researchers interested in investigating latency of foliar infections and reexamining the role of foliar sporulation in fruit infection.

\section{ACKNOWLEDGMENTS}

The technical support of S. Linderman and financial support of the Michigan Agriculture Experiment Station is gratefully acknowledged.

\section{LITERATURE CITED}

1. Barksdale, T. H. 1967. Light induced in vitro sporulation of Colletotrichum coccodes causing tomato anthracnose. Phytopathology 57:1173-1175.

2. Byrne, J. M., Hausbeck, M. K., and Hammerschmidt, R. 1997. Conidial germination and appressorium formation of Colletotrichum coccodes on tomato foliage. Plant Dis. 81:715-718.

3. Byrne, J. M., Hausbeck, M. K., and Latin, R. X. 1997. Efficacy and economics of management strategies to control anthracnose fruit rot in processing tomatoes in the Midwest. Plant Dis. 81:1167-1172.

4. Dillard, H. R. 1988. Influence of temperature, $\mathrm{pH}$, osmotic potential, and fungicide sensitivity on germination of conidia and growth from sclerotia of Colletotrichum coccodes in vitro. Phytopathology 78:1357-1361.

5. Dillard, H. R. 1989. Effect of temperature, wetness duration, and inoculum density on infection and lesion development of Colletotrichum coccodes on tomato fruit. Phytopathology 79:1063-1066.

6. Esquerré-Tugayé, M. T., Mazua, D., Barthe, J. P., Lafitte, C., and Touzé, A. 1992. Mechanisms of resistance to Colletotrichum species. Pages 121-133 in: Colletotrichum: Biology, Pathology and Control. J. A. Bailey and M. J. Jeger, eds. CAB International, UK.

7. Farley, J. D. 1972. A selective medium for assay of Colletotrichum coccodes in soil. Phytopathology 62:1288-1293.

8. Farley, J. D. 1976. Survival of Colletotrichum coccodes in soil. Phytopathology 66:640-641.
9. Flaishman, M. A., and Kolattukudy, P. E 1994. Timing of fungal invasion using host's ripening hormone as a signal. Proc. Natl. Acad. Sci. 91:6579-6583.

10. Fulton, J. P. 1948. Infection of tomato fruits by Colletotrichum phomoides. Phytopathology 38:235-246.

11. Hausbeck, M. K., and Linderman, S. D. 1992. Influence of dew period and temperature on infection of tomato foliage by Colletotrichum coccodes. (Abstr.) Phytopathology 82:1091.

12. Hornby, D. 1968. Studies on Colletotrichum coccodes. III: Some properties of the fungus in soil and in tomato roots. Trans. Br. Mycol. Soc. 51:541-553.

13. Illman, W. I. 1960. Anthracnose disease of tomato. Ph.D. diss. University of Western Ontario, London, Canada.

14. Illman, W. I., Ludwig, R. A., and Farmer, J. 1959. Anthracnose of canning tomatoes in Ontario. Can. J. Bot. 37:1237-1246.

15. Kendrick, J. B., and Walker, J. C. 1948. Anthracnose of tomato. Phytopathology 38:247260.

16. Kubo, Y., and Furusawa, I. 1991. Melanin biosynthesis: Prerequisite for successful invasion of the plant host by appressoria of Colletotrichum and Pyricularia. Pages 205-218 in: The Fungal Spore and Disease Initiation in Plants and Animals. G. T. Cole and H. C. Hoch, eds. Plenum Press, New York.

17. Kubo, Y., Suzuki, K., Furusawa, I., Ishida, N., and Yamamoto, M. 1982. Relation of appressorium pigmentation and penetration of nitrocellulose membranes by Colletotrichum lagenarium. Phytopathology 72:498-501.

18. Michigan Department of Agriculture. 1996. Michigan Agricultural Statistics 1995-1996. Michigan Agricultural Statistics Service, Lansing, MI.

19. Pantidou, M. E., and Schroeder, W. T. 1955. Foliage as a source of secondary inoculum for tomato anthracnose. Phytopathology 45:338345.

20. Prechuer, R. J., Bennett, M. A., Riedel, R. M., Wiese, K. L., and Dudek, J. 1992. Management of fungicide residues on processing tomatoes. Plant Dis. 76:700-702.

21. Prusky, D., Ascarelli, A., and Jacoby, B. 1984 Lack of involvement of nutrients in the latency of Colletotrichum gloeosporioides in unripe avocado fruits. Phytopathol. Z 110:106-109.

22. Prusky, D., Keen, N. T., and Eaks, I. 1983. Further evidence for the involvement of a preformed antifungal compound in the latency of Colletotrichum gloeosporioides on unripe avocado fruits. Physiol. Plant Pathol. 22:189-198.

23. Prusky, D., Keen, N. T., Sims, J. J., and Midland, S. L. 1982. Possible involvement of an antifungal diene in the latency of Colletotrichum gloeosporioides on unripe avocado fruits. Phytopathology 72:1578-1582.

24. Prusky, D., Kobiler, I., Jacoby, B., Sims, J. J. and Midland, S. L. 1985. Inhibitors of avocado lipoxygenase: Their possible relationship with the latency of Colletotrichum gloeosporioides. Physiol. Plant Pathol. 27:269-279.

25. Tu, J. C. 1980. The ontogeny of the sclerotia of Colletotrichum coccodes. Can. J. Bot. 58:631-636.

26. Younkin, S. B., and Dimock, A. W. 1944. Foliage infections of Lycopersicon esculentum by Colletotrichum phomoides. Phytopathology 34:976-977.

27. Zulfiqar, M., Brlansky, R. H., and Timmer, L. W. 1996. Infection of flower and vegetative tissues of citrus by Colletotrichum acutatum and C. gloeosporioides. Mycologia 88(1): 121-128. 